\title{
Developing a hybrid multi-criteria model for investment in stock exchange
}

\author{
Safar Fazli and Hadi Jafari*
}

Department of Management, Imam Khomeini International University (IKIU), Qazvin, Iran

\begin{tabular}{|c|c|}
\hline A R T I C L E I N F O & A B S T R A C T \\
\hline $\begin{array}{l}\text { Article history: } \\
\text { Received June } 2,2011 \\
\text { Received in Revised form } \\
\text { October, } 19,2011 \\
\text { Accepted } 8 \text { January } 2012 \\
\text { Available online } \\
\text { 11 January } 2012 \\
\text { Keywords: } \\
\text { Investment } \\
\text { Stock Exchange } \\
\text { DEMATEL } \\
\text { VIKOR } \\
\text { ANP } \\
\text { MCDM }\end{array}$ & $\begin{array}{l}\text { One of the main challenges in Stock Market is to choose an appropriate combinations of } \\
\text { various assets. The aim of this study is to propose a hybrid method, which is able to survey one } \\
\text { problem with some criteria that it is very good for investment problem. In this study, we use a } \\
\text { hybrid multiple criteria decision-making (MCDM) model, which shows the dependent } \\
\text { relationships among criteria with DEMATEL method to build a relations-structure among } \\
\text { criteria. We then use Analytical Network Process (ANP) to determine the relative weights of } \\
\text { each criterion with dependence and feedback, and the VIKOR method is implemented to rank } \\
\text { and select the best alternatives for investment. This study is in stock exchange in Iran to select } \\
\text { the best stocks and the data are gathered through the years (2006-2010). There are a lot of } \\
\text { methods to rank and select of firms that most of the methods just do one, ranking or selecting; } \\
\text { but the used method in this study not only ranks the firms but also determines which firms } \\
\text { (stocks) are best for investment, so that in this study } 2 \text { of } 50 \text { firms are proposed for investment. }\end{array}$ \\
\hline
\end{tabular}

\section{Introduction}

Investment is one of the most important challenging decision making problem among investors, managers, stockholders, etc. The most popular issue is to find a tradeoff between return and risk in portfolio selection (Bermúdez et al., 2007). There are technical indicators for studying price trends of each stock such as moving averages, relative strength index (RSI), and moving average convergence divergence (MACD) (Abdollahzadeh, 2002). However, most of these techniques just use one criterion for predicting which stocks are the best to invest. We may also use multiple criteria decision making (MCDM) techniques to consider various important criteria for decision making (Babic \& Plazibat, 1998). There are also some institutes, which could help investors find better investment strategies. For example Soenen \& Johnson (2003) used price and transaction level or in another study, S\&P indicators and the level of firms that are upper and downer than this ranking was surveyed (Polonchek \& Krehbiel, 1994).

\footnotetext{
* Corresponding author. Tel: +98 913 2338076; Fax: +98 2813780021

E-mail addresses: mrhadi66@gmail.com (H. Jafari) 
MCDM is one of the most known models of decision making that is able to solve problems with some criteria and some alternatives. There are a lot of methods to solve MCDM models like AHP, ANP, TOPSIS, and so on. For example, TOPSIS method was used in many studies like (Jiang, et al., 2011; Park, et al., 2011; Vahdani et al., 2011), or AHP method (Büyüközkan et al., 2011; Lee et al., 2010). Meanwhile; some studies combined these methods (e.g. Shen et al., 2011; Yang \& Tzeng, 2011). Some studies ranked the firms with MCDM models in financial aspects, for example Ertugrul and Karakaşoğlu (2009) with a combined FAHP and TOPSIS method ranked Turkish cement firms but these studies incorrectly assumed that the criteria in the decision process are independent, which is not true in the real-world, and on the other hand, the mentioned method only ranked the firms and it is not able to determines which firms are good alternatives for investment. Hence, the following combined method is proposed.

In this study, we use DEMATEL method to construct the interrelationship among criteria, and will also use the ANP method to determine the weights of criteria. We will then use the VIKOR method to rank and select the best firms for investment.

The rest of the paper is organized as follows. Section 2 is literature review, Section 3 presents the proposed method to determine the best stocks and firms for investment. Section 4 surveys a case study in stock exchange in Iran, discussion in section 5 and finally conclusion in section 6.

\section{2. literature review}

In this section, we introduce 50 more active companies in Iran and different application of MCDM models, through that we mention some financial ranking which was ranked by MCDM models and then, we represent the used criteria in this study for ranking and selecting 50 more activity companies in Iran.

\subsection{0 more activity companies in Iran}

Stock exchange in Iran publishes a list every three months as the 50 most active firms in Iran in terms of transactions. As mentioned before, the weakness of these ranking methods is that just one criterion is used and it does not prepare a good view for investors so we will rank this 50 firms with respect to a new combined MCDM model which surveys some financial criteria.

\subsection{Multiple criteria decision-making (MCDM)}

Multiple criteria decision making (MCDM) refers to the problem of selecting among alternatives associated with multiple criteria (Hwang \& Yoon, 1981). A number of methods are proposed to solve MCDM models from different perspectives; including performance, financial, improvement, etc.

Analytical hierarchy process (AHP) is one of the earliest and most well known MCDM methods. For example, Poh and Ang (1999) presented a policy and planning problem related to the best fuel alternative for Singapore land transportation in the years 2020-2030. They used AHP to evaluate four possible plans or scenarios and six criteria. They found that the complementary policy of providing the necessary infrastructure to facilitate the recharging of electric vehicles would lead to even better results.

Other studies also used this method, the main advantage is being simple and understandable but the AHP method assumes that the factors presented in the hierarchical structure are independent, which is not true in many real-world problems. Some studies used AHP in fuzzy environment like (Chamodrakas et al., 2010), although there is the mentioned weakness yet. Another common method is TOPSIS, which is used in many studies. For example, $\mathrm{Yu}$ and $\mathrm{Hu}$ (2010) proposed an integrated fuzzy multi-criteria approach for the performance evaluation of multiple manufacturing plants. Their 
evaluation procedure consists of the following steps: (1) identify the evaluation dimensions and criteria; (2) assess the importance of each criterion by the voting method; (3) aggregate the assessments for lower-level criteria of each dimension; (4) represent the performance assessment for each criterion by fuzzy numbers; (5) use TOPSIS as the main device in ranking the performance of multiple plants. This method has some strengths and weaknesses, for example simplicity and existence of positive and negative criteria coincide in the model is considered as the strength point and independent relation between the criteria is the weakness of this method. As we said, the AHP method assumes that the factors presented in the hierarchical structure are independent and in the other side TOPSIS needs criteria with independent relation, which lead us to use analytical network process (ANP).

Yüksel and Dağdeviren (2007) used ANP method to rank SO, WO, ST, and WT as alternatives in SWOT model. They used four criteria include: strengths, weaknesses, opportunities, and threats and fourteen sub criteria. The ANP technique, which enables measuring inter-factor dependencies, was utilized in this work and they found that the dependency among SWOT factors affects both the strategy selection and the strategy priority order.

The ANP method is good because of surveys inter-factor dependencies but it suffers from a weakness for identifying relation structure since it is necessary that one group of experts gather in a unique place and determine the relationship structure, to solve this weakness the DEMATEL method is proposed.

Liou and Chuang (2010) applied a combined method to rank outsourcing providers in Taiwanese airline. They identified four criteria including compatibility, quality, cost, and risk and eleven sub criteria. They determined relation structure between criteria with DEMATEL and with respect to this structure relation, they used ANP method to determine weights of each criteria. Finally, they ranked four outsourcing providers as alternatives.

\subsection{Survey criteria in this study}

In this study, we need to have some criteria, which is suitable for investment. The best criteria for this purpose are common financial ratios include Liquidity, Financial Leverage, Activity, Profitability, and Growth (Ertuğrul \& Karakaşoğlu, 2009).

\section{Proposed model: a novel hybrid model of DEMATEL, ANP, and VIKOR}

To build a relation-structure among criteria DEMATEL method is used, then the ANP is used to determine the relative weights of each criterion with dependence and feedback, and the VIKOR method is then used to rank and select the best alternatives for investment. Hence, in this section, we introduce the concepts of the DEMATEL (to establish the relation-structure model in evaluation problem), ANP (to determine criteria weights) and VIKOR (to prioritize alternatives) methods.

\subsection{The decision making trial and evaluation laboratory (DEMATEL)}

The Battelle Memorial Institute developed the DEMATEL method project through its Geneva Research Centre (Gabus \& Fontela, 1973). By using DEMATEL, we could quantitatively extract the interrelationship between multiple criteria that were contained in the problem (Chang, 2009). The DEMATEL method can be summarized in the following steps:

Step 1: calculate the initial average matrix by scores. Respondents are required to point out the degree of direct influence among each element $i$ exerts on each element $j$ of others, as indicated by $a_{i j}$ according to an integer scale (scores) ranging from 0 to 4 , representing: "no influence (0);" "low influence (1);" " "medium influence (2);" "high influence (3);" and "very high influence (4)." From 
any group of direct respondent matrices, we derive an average matrix A. In this case, each element of this average matrix will be the mean of the same elements in different direct matrices of the respondents.

Step 2: Calculate the normalized direct-influence matrix $S$. Matrix $S$ can be calculated by normalizing A through Eq. (1) and Eq. (2).

$S=m . A$

$\mathrm{m}=\min \left[\frac{1}{\max _{i} \sum_{j=1}^{n}\left|a_{i j}\right|}, \frac{1}{\max _{j} \sum_{i=1}^{n}\left|a_{i j}\right|}\right]$

Step 3: Derive the total direct-influence matrix $T$. $T$ can be derived by using a formula (3), where I denotes the identity matrix; i.e., a continuous decrease of the indirect effects of problems along the powers of $\mathrm{S}$, e.g., $\mathrm{S}^{2}, \mathrm{~S}^{3}, \ldots, \mathrm{S}^{\mathrm{q}}$ and $\lim _{q \rightarrow \infty} \mathrm{S}^{\mathrm{q}}=[0]_{n \times n}$, where $\mathrm{S}=\left[S_{i j}\right]_{n \times n}, 0 \leq S_{i j} \leq 1$ and $0 \leq \sum_{i} S_{i j}$ or $\sum_{j} S_{i j} \leq 1$ only one column or one row sum equals 1 , but not all. The total-influence matrix is listed as follows:

$$
\begin{aligned}
\mathrm{T} & =\mathrm{S}+\mathrm{S}^{2}+\cdots+\mathrm{S}^{\mathrm{q}} \\
& =\mathrm{S}\left(\mathrm{I}+\mathrm{S}+\mathrm{S}^{2}+\cdots+\mathrm{S}^{\mathrm{K}-1}\right)(\mathrm{I}-\mathrm{S})(\mathrm{I}-\mathrm{S})^{-1} \\
& =\mathrm{S}\left(\mathrm{I}-\mathrm{S}^{\mathrm{q}}\right)(\mathrm{I}-\mathrm{S})^{-1}
\end{aligned}
$$

When ${ }^{\mathrm{q}} \rightarrow \infty, \mathrm{S}^{\mathrm{q}}=[0]_{n \times n}$, then

$\mathrm{T}=\mathrm{S}(\mathrm{I}-\mathrm{S})^{-1}$

Where $\mathrm{T}=\left[t_{i j}\right]_{n \times n}, \mathrm{i}, \mathrm{j}=1,2, \ldots, \mathrm{n}$.

Step 4: Set threshold value and obtain the impact relation map. Setting a threshold value, $p$, to filter the obvious effects denoted by the elements of matrix $T$, is necessary to explain the relationship structure between the elements. Based on the matrix $T$, each element $t_{i j}$ of matrix $T$ provides information about how element $i$ affects element $j$. To reduce the complexity of the impact relations map (IRM), the decision-maker must set a threshold value for the influence level. Only some elements, whose influence level in matrix $T$ is higher than the threshold value, can be chosen and converted into the IRM (Jerry et al., 2011; Liou \& Chuang, 2010; Liou et al., 2007).

\subsection{The analytic network process (ANP)}

The ANP is a generalization of the AHP to solve problems where there are relationships among criteria or among criteria with alternatives or reverse (Saaty, 1996). The method of the ANP can be described as follows:

The first step of the ANP is to compare the criteria in whole system to form the supermatrix. This is done through pair-wise comparisons by asking "How much importance/influence does a criterion have compared to another criterion with respect to our interests or preferences?" The relative importance value can be determined using a scale of 1-9 to represent equal importance to extreme importance (Saaty, 1980, 1996). The general form of the supermatrix can be described as follows:

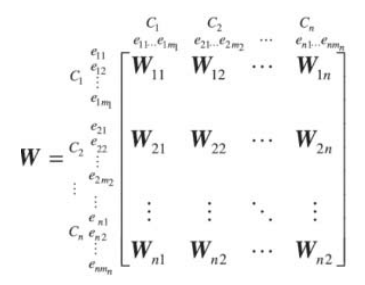


where $\mathrm{C}_{\mathrm{n}}$ denotes the $n^{\text {th }}$ cluster, $\mathrm{e}_{\mathrm{nm}}$ denotes the $m^{\text {th }}$ element in $n^{\text {th }}$ cluster, and $\mathrm{W}_{\mathrm{ij}}$ is the principal eigenvector of the influence of the elements compared in the $j^{\text {th }}$ cluster to the $i^{\text {th }}$ cluster. In addition, if the $j^{\text {th }}$ cluster has no influence to the $i^{\text {th }}$ cluster, then $\mathrm{W}_{\mathrm{ij}}=[0]$. The form of the supermatrix depends on the variety of the structure. For example, if the structure of the system is shown as Fig. 1, the unweighted supermatrix $W$, which contains local priorities derived from the pair-wise comparisons throughout the network, is illustrated as follows:

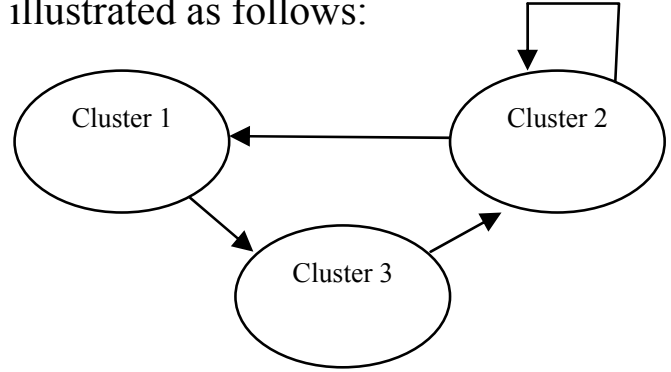

Fig. 1. Relation structure between clusters

$C_{1} \quad C_{2} \quad C_{3}$

$C_{1}$
$C_{2}$
$C_{3}$$\left[\begin{array}{ccc}0 & w_{12} & 0 \\ 0 & w_{22} & w_{23} \\ w_{31} & 0 & 0\end{array}\right]$

$\mathrm{W}_{12}$ is a matrix, which represents the weights of cluster 1 with respect to cluster 2 , matrix $\mathrm{W}_{23}$ represents the weights of cluster 2 with respect to cluster 3 , and matrix $\mathrm{W}_{31}$ represents the weights of cluster 3 with respect to cluster 1 . In addition, matrix $W_{22}$ is denoted as the inner dependence and feedback within cluster 2. After forming the supermatrix, the weighted supermatrix is derived by transforming all column sums exactly to unity. Then, the weighted supermatrix can be raised to limiting powers, as in Eq. (6), to calculate the overall priorities.

$\lim _{k \rightarrow \infty} W^{K}$

\subsection{The VIKOR method}

Opricovic (1998) introduced VIKOR method. In the complex multi-criteria systems, this method is used (Opricovic \& Tzeng, 2004). The basic concept of VIKOR lies in defining the positive and negative ideal solutions. The positive ideal solution shows the alternative with the highest value, while the negative ideal solution shows the alternative with lowest value (Liou \& Chuang, 2010).

The VIKOR method can be summarized in the following steps:

Step 1: Make the decision matrix

With respect to the criteria and alternatives, decision matrix is as follows,

$\left(\begin{array}{ccc}x_{11} & \ldots & x_{1 n} \\ \vdots & \ddots & \vdots \\ x_{m 1} & \cdots & x_{m n}\end{array}\right)$

where $\mathrm{x}_{\mathrm{ij}}$ denotes to the performance of alternative $i(i=1,2, \ldots, m)$ in relation with criterion $j(j=1,2$, $\ldots, n)$.

Step 2: Normalizing the decision matrix

At this step, the normalized elements of matrix can be derived by using a Eq. (9). Normalized decision matrix is as follows, 
$\left(\begin{array}{ccc}f_{11} & \ldots & f_{1 n} \\ \vdots & \ddots & \vdots \\ f_{m 1} & \cdots & f_{m n}\end{array}\right)$

where

$f_{i j}=\frac{x_{i j}}{\sqrt{\sum_{i=1}^{m} x_{i j}^{2}}}$

Step 3: Determine the weight of each criterion

The weight of each criterion in this problem was determined with ANP method.

Step 4: Determine the best $f_{j}^{*}$ and the worst $f_{j}^{-}$

The best $f_{j}^{*}$ for positive and negative criteria is as follows,

$f_{j}^{*}=\max _{i} f_{i j}$

$f_{j}^{*}=\min _{i} f_{i j}$

The worst $f_{j}^{-}$for positive and negative criteria is as follows,

$f_{j}^{-}=\min _{i} f_{i j}$

$f_{j}^{-}=\max _{i} f_{i j}$

where $f_{i j}$ is the value of $i^{\text {th }}$ criterion function for the alternative $j$.

Step 5: Compute the value $S_{i}$ and $R_{i}, \mathrm{i}=1,2, \ldots, \mathrm{i}$, by the relations

$S_{i}=\sum_{j=1}^{n} w_{j} \frac{f_{j}^{*}-f_{i j}}{f_{j}^{*}-f_{j}^{-}}$

$R_{i}=\operatorname{Max}\left\{w_{j} \frac{f_{j}^{*}-f_{i j}}{f_{j}^{*}-f_{j}^{-}}\right\}$

where $w_{j}$ are the weights of criteria, expressing their relative importance.

Step 6: Compute the value $Q_{i}, i=1,2, \ldots, i$, by the relations

$Q_{i}=v\left[\frac{S_{i}-S^{-}}{S^{*}-S^{-}}\right]+(1-v)\left[\frac{R_{i}-R^{-}}{R^{*}-R^{-}}\right]$

where

$S^{-}=\operatorname{Min} S_{i} \quad S^{*}=\operatorname{Max} S_{i} \quad R^{-}=\operatorname{Min} R_{i} R^{*}=\operatorname{Max} R_{i}$

and $v$ is introduced as weight of strategy of "the majority of criteria" (or "the maximum group utility"), here we use $v=0.5$.

Step 7: Rank the alternatives, sorting by the values $R, S$ and $Q$, in decreasing order.

If we arrange the alternatives according to value $Q$ (in decreasing order) we have ranked the alternatives, but to select the best alternatives the following two conditions must be satisfied.

Condition 1: Acceptable advantage:

$Q\left(A_{2}\right)-Q\left(A_{1}\right) \geq \frac{1}{n-1}$ 
where $A_{2}$ is the alternative with second position in the ranking list by $Q ; A_{1}$ is the alternative with first position and $n$ is the number of alternatives.

Condition 2: Acceptable stability in decision making: Alternative $A_{1}$ must also be the best ranked by $\mathrm{S}$ or/and $\mathrm{R}$. If one of the conditions is not satisfied, then a set of compromise solutions is proposed, which consists of:

- If only condition 2 is not satisfied, alternatives $A_{1}$ and $A_{2}$ is selected, or

- Alternatives $A_{1}, A_{2}, \ldots, A_{m}$ if condition 1 is not satisfied; and $A_{m}$ is determined by the relation (18) for maximum $\mathrm{m}$ (Huang, Yan, \& Ji, 2008; Opricovic \& Tzeng, 2007; Wu, Lin, \& Chang, 2011).

$Q\left(A_{m}\right)-Q\left(A_{1}\right)<\frac{1}{n-1}$

\section{Empirical example}

In this section, an empirical study for the selection of stock in the stock exchange is used to illustrate the feasibility of the proposed method.

\subsection{Problem descriptions}

In this study, we want to survey which stocks are the best for investment in stock exchange in Iran. Stock exchange in Iran publishes a list every three months as the 50 more active firms in Iran. Table 1 is a sample of the most active firms in 2010.

\section{Table 1}

List of 50 more active firms in stock exchange in 2010

\begin{tabular}{|c|c|c|c|}
\hline 1 & Saipa & 26 & Iran Leasing \\
\hline 2 & Boali Investment Institute & 27 & Toka Foulad Investment Institute \\
\hline 3 & Ghadir Investment Institute & 28 & Azar Ab Industry \\
\hline 4 & Iran Khodro & 29 & Golgohar Iron Ore \\
\hline 5 & Fars \& Khozestan Cement & 30 & Tose Melli Investment Institute \\
\hline 6 & Rayan Saipa Leasing & 31 & Tehran Cement \\
\hline 7 & Saderat Bank & 32 & Omid Investment Institute \\
\hline 8 & Chadormelo Industrial and Mining & 33 & Kashsn Amirkabir Foulad \\
\hline 9 & Tejarat Bank & 34 & Takin Ko Corrosion Control \\
\hline 10 & Melli Iranian Copper Industries & 35 & Informatics Services \\
\hline 11 & Development of Mines \& Metals & 36 & Toli Pers \\
\hline 12 & Sanat \& Madan Investment Institute & 37 & Pars Mehrkam \\
\hline 13 & Isfehan Petrochemical & 38 & Sina Bank \\
\hline 14 & Rana Investment Institute & 39 & Mashhad Making Ring \\
\hline 15 & Development of Behshahr Industry & 40 & Khodro Shargh Electric \\
\hline 16 & Inranian Making Meter & 41 & Sandogh Bazneshastegi Investment Institute \\
\hline 17 & Iranian Behshahr Industy Group & 42 & Shazand Petrochemical \\
\hline 18 & Dorod Farsit Factory & 43 & Melli Bank Investment Institute \\
\hline 19 & Jaberebne Hayyan Pharmacy & 44 & Shahed Investment Institute \\
\hline 20 & Karafarin Bank & 45 & Iranian Car Part \\
\hline 21 & Mellat Bank & 46 & Isfehan Foulad \\
\hline 22 & Saypa Azin & 47 & Yazd Joshkab Industry \\
\hline 23 & Sobhan pharmacy Group & 48 & Dorod Cement \\
\hline 24 & Iran Transfo & 49 & Niro Moharreke \\
\hline 25 & Eghtesad Novin Bank & 50 & Bama \\
\hline
\end{tabular}




\subsection{Selection criteria}

As mentioned before, there are different criteria, which are used for ranking stocks but in this study we need comprehensive criteria, so common financial ratios are used. These ratios are: Liquidity Ratios, Financial Leverage Ratios, Activity Ratios, Profitability Ratios, and Growth Ratios (Ertuğrul \& Karakaşoğlu, 2009).

\section{Definition 1.}

Liquidity ratios. Liquid asset can be easily converted to cash at a fair market value and a firm's liquidity position deals with the question: Will the firm be able to meet its current obligations? (Weston \& Brigham, 1993).

\section{Definition 2.}

Financial leverage ratios. Financial leverage ratios indicate a firm's capacity to meet short- and longterm debt obligations. These ratios survey which non-equity capital is used in a firm and the long term ability of a firm to meet payments to non-equity suppliers of capital (Foster, 1978).

\section{Definition 3.}

Activity ratios (Asset turnover ratios). Activity ratios indicate how much a firm has invested in a particular type of asset relative to the revenue the asset is producing(Moyer et al., 1992).

\section{Definition 4.}

Profitability ratios. Profitability ratios indicate the ability of a firm to generate revenues in excess of expenses (Foster, 1978).

\section{Definition 5.}

Growth ratios. Growth ratios indicate how well the position of the firm in the industry (Ertugrul \& Karakaşoğlu, 2009). Liquidity ratio includes current ratio (C1), Quick ratio (C2) and Cash ratio (C3). Financial leverage ratio includes dept ratio (C4), Shareholders' equality to assets (C5), Fixed assets to shareholders' equity (C6), Fixed assets to long term debts (C7). Activity ratios consists of five items including account receivable ratio (C8), inventory turnover ratio (C9), current assets turnover ratio $(\mathrm{C} 10)$, total assets turnover ratio $(\mathrm{C} 11)$ and account payable turnover ratio $(\mathrm{C} 12)$.

Profitability ratio also includes net profit margin (C13) and return on equity (C14). Finally, growth ratio consists of sales growth $(\mathrm{C} 15)$, operating profit growth $(\mathrm{C} 16)$, shareholders' equity growth $(\mathrm{C} 17)$ and assets growth $(\mathrm{C} 18)$.

\subsection{Measuring the relationships among dimensions}

Since the stock selection in stock exchange is complex, it is not true to assume the elements within systems are independent. Therefore, we sought to find the important criteria of evaluation systems and measure the relationships among these dimensions. According to the DEMATEL procedures described in Section 3.1, managers were asked to score the relationships among dimensions. The average initial direct-relation matrix $\mathrm{A}$ is a $5 \times 5$ matrix obtained by pair-wise comparisons in terms of influences and directions between dimensions, as shown in Table 2. As matrix $A$ shows, the normalized direct-relation matrix $D$ is calculated through Eq. (1) and Eq. (2). 
Table 1

Initial influence matrix

\begin{tabular}{|c|c|c|c|c|c|}
\hline & $\begin{array}{l}\text { Liquidity } \\
\text { Ratios }\end{array}$ & $\begin{array}{c}\text { Financial } \\
\text { Leverage Ratios }\end{array}$ & $\begin{array}{l}\text { Activity } \\
\text { Ratios }\end{array}$ & $\begin{array}{c}\text { Profitability } \\
\text { Ratios }\end{array}$ & $\begin{array}{l}\text { Growth } \\
\text { Ratios }\end{array}$ \\
\hline Liquidity Ratios & 0 & 1.75 & 0 & 0.75 & 0.25 \\
\hline Financial Leverage Ratios & 0 & 0 & 0 & 0.75 & 0.25 \\
\hline Activity Ratios & 1.25 & 1.75 & 0 & 1 & 0.25 \\
\hline Profitability Ratios & 1.25 & 0.75 & 1.5 & 0 & 0.25 \\
\hline Growth Ratios & 1.5 & 1.25 & 2.25 & 1.75 & 0 \\
\hline
\end{tabular}

Then, by using Eq. (3), total-influence matrix $T$ is derived as indicated in Table 3. According to the results of DEMATEL, the threshold value 0.07 was decided through managers' discussions. Based on the above threshold value, the IRM of DEMATEL method is obtained and shown in Fig. 2.

Table 2

Total influence matrix

\begin{tabular}{llllll}
\hline & $\begin{array}{l}\text { Liquidity } \\
\text { Ratios }\end{array}$ & $\begin{array}{l}\text { Financial } \\
\text { Leverage Ratios }\end{array}$ & $\begin{array}{l}\text { Activity } \\
\text { Ratios }\end{array}$ & $\begin{array}{l}\text { Profitability } \\
\text { Ratios }\end{array}$ & $\begin{array}{l}\text { Growth } \\
\text { Ratios }\end{array}$ \\
\hline Liquidity Ratios & 0.0571 & 0.3202 & 0.0593 & 0.1773 & 0.0598 \\
Financial Leverage Ratios & 0.0454 & 0.0484 & 0.0471 & 0.1408 & 0.0475 \\
Activity Ratios & 0.263 & 0.3899 & 0.0804 & 0.2517 & 0.0735 \\
Profitability Ratios & 0.2741 & 0.2798 & 0.2731 & 0.1207 & 0.0721 \\
Growth Ratios & 0.4021 & 0.4678 & 0.4529 & 0.4399 & 0.0653 \\
\hline
\end{tabular}

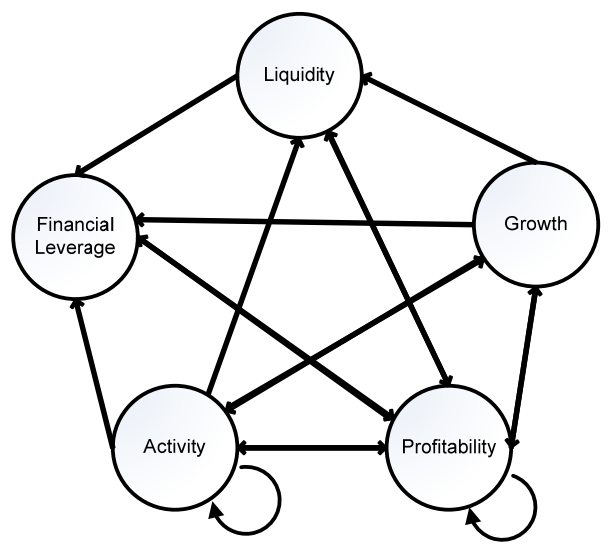

Fig. 2. Impact relationship map (IRM)

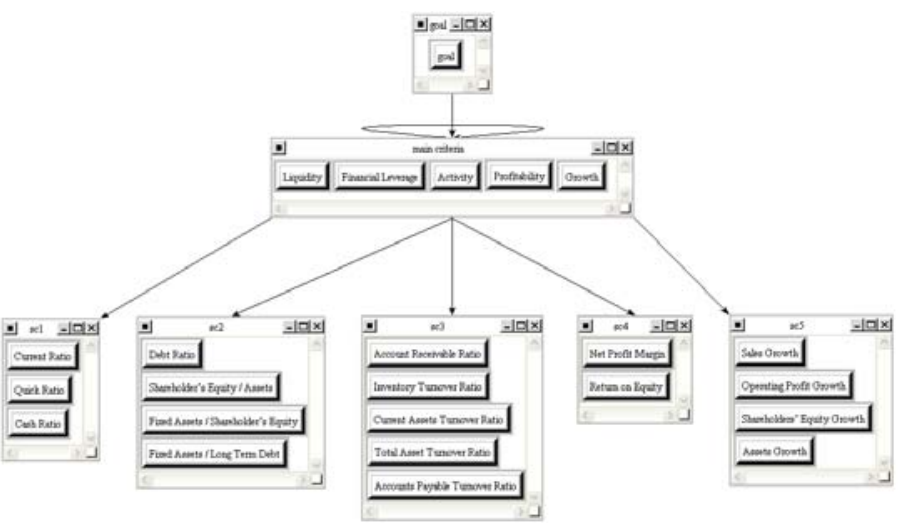

Fig. 3. The overall model

\subsection{Deriving the weights of criteria in evaluating systems}

After determining the relationship structure between dimensions of the evaluating systems, the ANP method is applied to derive the weights of the criteria. For example, the managers were asked to respond to a series of questions, such as "For the relationship, how much more important is one of the considered criteria over another?"

These pair-wise comparisons are based on Saaty's 9-point scale and represent the importance of one element over another (where 1 = equal importance and $9=$ extreme importance of one element over another) (Ertuğrul \& Karakaşoğlu, 2009). In this study, Super Decision Software was used to calculate the weight of each criterion. We can see the overall model in Fig. 3 and the limited supermatrix in Table 4. 


\section{Table 3}

The limited supermatrix

\begin{tabular}{|c|c|c|c|c|c|c|c|c|c|c|c|c|c|c|c|c|c|c|}
\hline & $\mathrm{c} 1$ & $\mathrm{c} 2$ & c3 & $\mathrm{c} 4$ & $\mathrm{c5}$ & 6 & c7 & c8 & c9 & c10 & c11 & $\mathrm{c} 12$ & $\mathrm{c} 13$ & c14 & $\mathrm{c} 15$ & $\mathrm{c} 16$ & c17 & c18 \\
\hline 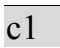 & 025 & & & & & & & 0 & 0.0 & & , & & & & 3 & & & 25 \\
\hline & 36 & & & & & & & & & & & & & & & & & \\
\hline & .067 & 06 & & & 0 & & & & & & & & & & & & & 67 \\
\hline & & & & & & & & & & & & & & & & & & \\
\hline & .029 & 02 & 0. & & 0. & 0.1 & 0 . & 0 . & 0. & 0 & 9 & 0 & 0 & ) & & & & 29 \\
\hline & & & & & & & & & & & & & & & & & & $A$ \\
\hline & & & & & & & & & & & & & & & & & & 8 \\
\hline & .035 & & & & & & & & & & & & & & & & & 35 \\
\hline & 61 & & & & & & & & & & & & & & & & & 61 \\
\hline & 0.029 & 029 & 0.0 & 0.029 & 0.029 & 0.029 & 0. & 0.029 & 0.029 & 0. & 0.029 & 0. & & 9 & 0. & & & 29 \\
\hline & 0.066 & 66 & & & & & & & & & & & & & & & & 066 \\
\hline & & & & & & & & & & & & & & & & & & 19 \\
\hline & 9 & & & & & & & & & & & & & & & & & 19 \\
\hline & & & & & & & & & & & & & & & & & & 59 \\
\hline & 661 & & & & & & & & & & & & & & & & & 961 \\
\hline & & & & & & & & & & & & & & & & & & 065 \\
\hline & & & & & & & & & & & & & & & & & & 08 \\
\hline & & & & & & & & & & & & & & 6 & & & & 0.016 \\
\hline
\end{tabular}

\subsection{Using VIKOR to rank and select the best stock in stock exchange}

The data for these 18 sub criteria are gathered through from 2006 to 2010 from Tehran stock exchange. For each criterion and each ratio, we have used the average of five years data for each criterion we can get a unique number for each criterion for each alternative. Then with respect to the calculated weights in the previous sections and data gathered from Tehran stock exchange, we can rank the alternatives with VIKOR method and then select the best alternatives for investment.

\section{Table 4}

Results of the VIKOR method

\begin{tabular}{|c|c|c|c|c|c|c|c|c|c|}
\hline & $\mathrm{S}$ & $\mathrm{R}$ & $Q$ & Rank & & $\mathrm{S}$ & $\mathrm{R}$ & $\mathrm{Q}$ & Rank \\
\hline$\overline{\mathrm{A} 1}$ & 0.76 & 0.14 & 0.49 & 25 & A26 & 0.73 & 0.16 & 0.54 & 33 \\
\hline A2 & 0.76 & 0.21 & 0.70 & 43 & A27 & 0.72 & 0.16 & 0.52 & 29 \\
\hline A3 & 0.69 & 0.17 & 0.51 & 27 & A28 & 0.89 & 0.26 & 1.00 & 50 \\
\hline A4 & 0.72 & 0.15 & 0.47 & 20 & A29 & 0.69 & 0.08 & 0.25 & 4 \\
\hline A5 & 0.74 & 0.19 & 0.62 & 38 & A30 & 0.60 & 0.19 & 0.44 & 18 \\
\hline A6 & 0.72 & 0.10 & 0.34 & 8 & A31 & 0.74 & 0.14 & 0.47 & 23 \\
\hline A7 & 0.76 & 0.23 & 0.76 & 47 & A32 & 0.62 & 0.17 & 0.40 & 15 \\
\hline A8 & 0.70 & 0.12 & 0.37 & 10 & A33 & 0.83 & 0.20 & 0.77 & 49 \\
\hline A9 & 0.80 & 0.20 & 0.71 & 45 & A34 & 0.50 & 0.10 & 0.05 & 1 \\
\hline A10 & 0.66 & 0.11 & 0.28 & 6 & A35 & 0.72 & 0.12 & 0.38 & 12 \\
\hline A 11 & 0.67 & 0.18 & 0.51 & 26 & A36 & 0.76 & 0.12 & 0.47 & 21 \\
\hline A 12 & 0.75 & 0.21 & 0.68 & 42 & A37 & 0.83 & 0.20 & 0.75 & 46 \\
\hline A 13 & 0.74 & 0.14 & 0.47 & 22 & A38 & 0.74 & 0.17 & 0.55 & 34 \\
\hline A14 & 0.64 & 0.16 & 0.41 & 16 & A39 & 0.81 & 0.17 & 0.66 & 40 \\
\hline A 15 & 0.72 & 0.19 & 0.60 & 36 & A40 & 0.77 & 0.14 & 0.52 & 30 \\
\hline A 16 & 0.71 & 0.16 & 0.49 & 24 & A41 & 0.69 & 0.18 & 0.53 & 32 \\
\hline A17 & 0.74 & 0.11 & 0.40 & 14 & A42 & 0.78 & 0.14 & 0.53 & 31 \\
\hline A18 & 0.76 & 0.17 & 0.60 & 37 & A43 & 0.76 & 0.21 & 0.71 & 44 \\
\hline A19 & 0.73 & 0.12 & 0.42 & 17 & A44 & 0.64 & 0.15 & 0.38 & 13 \\
\hline A20 & 0.74 & 0.13 & 0.46 & 19 & A45 & 0.49 & 0.15 & 0.25 & 5 \\
\hline A21 & 0.84 & 0.20 & 0.76 & 48 & A46 & 0.74 & 0.15 & 0.51 & 28 \\
\hline A22 & 0.81 & 0.16 & 0.63 & 39 & A47 & 0.70 & 0.09 & 0.30 & 7 \\
\hline A23 & 0.64 & 0.15 & 0.38 & 11 & A48 & 0.62 & 0.09 & 0.19 & 2 \\
\hline A24 & 0.70 & 0.12 & 0.36 & 9 & A49 & 0.83 & 0.17 & 0.67 & 41 \\
\hline A 25 & 0.77 & 0.16 & 0.59 & 35 & A50 & 0.58 & 0.13 & 0.24 & 3 \\
\hline
\end{tabular}


With respect to Eq. (14), Eq. (15) and Eq. (16), three indicators $S$, $R$, and $Q$ can be calculated for 50 firms and these indicators are shown in Table 5. The results show that alternatives $\mathrm{A}_{34}$ and $\mathrm{A}_{48}$ are the best alternatives for investment. In this study, the results indicate that $\mathrm{A}_{34}$ is the first choice followed by $A_{48}>A_{29}>A_{10}>\ldots>A_{28}$, where $A>B$ means $A$ is preferred to $B$, but $A_{34}$ and $A_{48}$ are our selected stock based on the proposed hybrid model. From Table4, it is observed that Return on Equity $(0.259)$ is the most important criterion in stock selection followed by Net Profit Margin (0.119), etc.

\section{Conclusion}

This study proposed a hybrid multiple criteria decision-making (MCDM) model, which shows the dependent relationships among criteria with DEMATEL and ANP method to determine the relative weights of each criterion. The method also used VIKOR method to rank and select the best alternatives for investment in stock exchange. A variety of methods were used to rank and select alternatives where each of them has some weaknesses and strengths but the proposed method of this study tries to diminish these weaknesses. For example, with DEMATEL method we are able to determine the correct relation between criteria, with ANP method we are able to survey the inter relations between criteria. This study was performed in stock exchange of Iran to select the best stocks. The alternatives were 50 more active firms and the data were gathered through from 2006 to 2010. The used criteria in this study were common financial ratios include Liquidity, Financial Leverage, Activity, Profitability, and Growth. This study showed that profitability ratio has the highest weigh in compare of other financial ratios and 2 of 50 firms are qualified for investment.

\section{References}

Abdollahzadeh, F. (2002). Investment management and Tehran Stock Exchange. Tehran, Iran: Pardazeshgaran press.

Babic, P., \& Plazibat, L. (1998). Ranking of enterprises based on multicriteria analysis. International journal of production economics, 56, 29 - 35.

Bermúdez, J. D., Segura, J. V., \& Vercher, E. (2007). A fuzzy ranking strategy for portfolio selection applied to the Spanish Stock Market. IEEE.

Büyüközkan, G., Çifçi, G., \& Güleryüz, S. (2011). Strategic analysis of healthcare service quality using fuzzy AHP methodology. Expert Systems with Applications, 38(8), 9407-9424.

Chamodrakas, I., Batis, D., \& Martakos, D. (2010). Supplier selection in electronic marketplaces using satisficing and fuzzy AHP. Expert Systems with Applications, 37(1), 490-498.

Chang, K.-H. (2009). Evaluate the orderings of risk for failure problems using a more general RPN methodology. Microelectronics Reliability, 49(12), 1586-1596.

Ertuğrul, I., \& Karakaşoğlu, N. (2009). Performance evaluation of Turkish cement firms with fuzzy analytic hierarchy process and TOPSIS methods. Expert Systems with Applications, 36, 702-715.

Foster, G. (1978). Financial statement analysis. Englewood Cliffs, NJ: Prentice-Hall.

Gabus, A., \& Fontela, E. (1973). Perceptions of the world problematique: communication procedure, communicating with those bearing collective responsibility. Geneva, Switzerland: Battelle Geneva Research Centre.

Huang, Y., Yan, Y., \& Ji, Y. (2008). Optimization of supply chain partner based on VIKOR method and G1 method. Paper presented at the International Seminar on Future BioMedical Information Engineering.

Hwang, C. L., \& Yoon, K. (1981). Multiple attribute decision making: Methods and applications. New York: Springer-Verlag.

Jerry Ho, W.-R., Tsai, C.-L., Tzeng, G.-H., \& Fang, S.-K. (2011). Combined DEMATEL technique with a novel MCDM model for exploring portfolio selection based on CAPM. Expert Systems with Applications, 38(1), 16-25. 
Jiang, J., Chen, Y.-w., Chen, Y.-w., \& Yang, K.-w. (2011). TOPSIS with fuzzy belief structure for group belief multiple criteria decision making. Expert Systems with Applications, 38(8), 94009406. doi: 10.1016/j.eswa.2011.01.128

Johnson, R., \& Soenen, L. (2003). Indicators of Successful Companies. European Management Journal, 21(3), 364-369. doi: 10.1016/s0263-2373(03)00050-1

Lee, S. K., Mogi, G., Lee, S. K., Hui, K. S., \& Kim, J. W. (2010). Econometric analysis of the R\&D performance in the national hydrogen energy technology development for measuring relative efficiency: The fuzzy AHP/DEA integrated model approach. International Journal of Hydrogen Energy, 35(6), 2236-2246.

Liou, J. J. H., \& Chuang, Y.-T. (2010). Developing a hybrid multi-criteria model for selection of outsourcing providers. Expert Systems with Applications, 37(5), 3755-3761.

Liou, J. J. H., Tzeng, G. H., \& Chang, H. C. (2007). A novel hybrid model for safety measurement of airlines. Journal of Air Transport Management, 13(4), 243-249.

Moyer, R. C., McGuigan, J. R., \& Kretlow, W. J. (1992). Contemporary financial management. USA: West Publishing Company.

Opricovic, S. (1998). Multicriteria optimization of civil engineering systems. Belgrade: Faculty of Civil Engineering.

Opricovic, S., \& Tzeng, G.-H. (2004). Compromise solution by MCDM methods: A comparative analysis of VIKOR and TOPSIS. European Journal of Operational Research, 156(2), 445-455. doi: 10.1016/s0377-2217(03)00020-1

Opricovic, S., \& Tzeng, G. H. (2007). Extended VIKOR method in comparison with outranking methods. European Journal of Operational Research, 178(2), 514-529.

Park, J. H., Park, I. Y., Kwun, Y. C., \& Tan, X. (2011). Extension of the TOPSIS method for decision making problems under interval-valued intuitionistic fuzzy environment. Applied Mathematical Modelling, 35(5), 2544-2556.

Poh, K. L., \& Ang, B. W. (1999). Transportation fuels and policy for Singapore: an AHP planning approach. Computers \& Industrial Engineering, 37, 507-525.

Polonchek, J., \& Krehbiel, T. (1994). Price and volume effects associated with changes in the Dow Jones averages. The quarterly review of economics and finance, 34(22), $305-316$.

Saaty, T. L. (1980). The analytic hierarchy process. New York: McGraw-Hill.

Saaty, T. L. (1996). Decision making with dependence and feedback: Analytic network process. Pittsburgh: RWS Publications.

Shen, Y.-C., Lin, G. T. R., \& Tzeng, G.-H. (2011). Combined DEMATEL techniques with novel MCDM for the organic light emitting diode technology selection. Expert Systems with Applications, 38(3), 1468-1481.

Vahdani, B., Mousavi, S. M., \& Tavakkoli-Moghaddam, R. (2011). Group decision making based on novel fuzzy modified TOPSIS method. Applied Mathematical Modelling, 35(9), 4257-4269. doi: 10.1016/j.apm.2011.02.040

Weston, J. F., \& Brigham, E. F. (1993). Essentials of managerial finance. India: Southwest Press.

Wu, H.-Y., Lin, Y.-K., \& Chang, C.-H. (2011). Performance evaluation of extension education centers in universities based on the balanced scorecard. Evaluation and Program Planning, 34(1), 37-50. doi: 10.1016/j.evalprogplan.2010.06.001

Yang, J. L., \& Tzeng, G.-H. (2011). An integrated MCDM technique combined with DEMATEL for a novel cluster-weighted with ANP method. Expert Systems with Applications, 38(3), 1417-1424.

Yu, V. F., \& Hu, K.-J. (2010). An integrated fuzzy multi-criteria approach for the performance evaluation of multiple manufacturing plants. Computers \& Industrial Engineering, 58(2), 269-277.

Yüksel, I., \& Dagdeviren, M. (2007). Using the analytic network process (ANP) in a SWOT analysis - A case study for a textile firm. Information Sciences, 177(16), 3364-3382. 